\title{
Hemophagocytic lymphohistiocytosis secondary to Falciparum malaria in a 5 year-old boy
}

\author{
Joana Almeida Santos • João Farela Neves • \\ Paulo Venâncio • Catarina Gouveia • Luís Varandas
}

Received: 11 May 2014 / Accepted: 20 May 2014 / Published online: 1 June 2014

(C) Springer-Verlag Berlin Heidelberg 2014

Dear Editor,

A previously healthy 5-year-old Portuguese boy presented to our Emergency Department (ED) with a history of 4 days of high fever and painful abdomen. He had been living in Mozambique (Matola) for the last year and didn't held malaria prophylaxis. At the time of admission, he was febrile and jaundiced, and a splenomegaly was noticed on physical examination. Initial laboratory data showed leucopenia, thrombocytopenia, high liver enzymes, direct hyperbilirubinemia, and elevated C-reactive protein. The diagnosis of malaria was confirmed by the presence of Plasmodium falciparum trophozoites in thin and thick blood films and by positive Plasmodium antigenemia. Despite a parasitemia of $<1 \%$, he was admitted and treated with IV quinine and clindamycin with diagnosis of severe malaria according to WHO criteria (Table 1). On the following days, his clinical condition deteriorated, presenting with high fever, hypotension, mucosal bleeding,

J. A. Santos $(\varangle) \cdot$ P. Venâncio

Pediatric Department, Hospital Dona Estefânia, Centro Hospitalar

Lisboa Central, EPE Rua Jacinta Marto, 1169-045 Lisbon, Portugal

e-mail: joanaasantos@gmail.com

C. Gouveia $\cdot$ L. Varandas

Pediatric Infectious Diseases Unit, Hospital Dona Estefânia, Centro

Hospitalar Lisboa Central, EPE Rua Jacinta Marto, Lisbon, Portugal

J. F. Neves

Primary Immunodeficiencies Unit and Pediatric Intensive Care Unit, Hospital Dona Estefânia, Centro Hospitalar Lisboa Central, EPE

Rua Jacinta Marto, Lisbon, Portugal

J. F. Neves

CEDOC, Chronic Diseases Study Centre, Faculty of Medical

Sciences, New University of Lisbon, Lisbon, Portugal

L. Varandas

Instituto de Higiene e Medicina Tropical, Faculty of Medical

Sciences, New University of Lisbon, Lisbon, Portugal pleural effusion, and ascites. Laboratory workout revealed disseminated intravascular coagulation, pancytopenia, cholestatic hepatitis, hypoalbuminemia, as well as elevated ferritin $(5,890 \mathrm{ng} / \mathrm{mL}$ ) and soluble CD25 (sIL2R $=4,352 \mathrm{U} / \mathrm{mL})$. Other co-infections were excluded (Table 1).

Despite the diagnosis of Falciparum malaria-associated hemophagocytic lymphohistiocytosis (HLH), he did not receive HLH-directed therapy and was treated with antimalaric drugs and supportive measures: packed red cells, platelets, fresh frozen plasma, cryoprecipitate, purified concentrate of fibrinogen, as well as inotropic support with dopamine (day 2 - 4). His clinical and laboratory condition slowly improved (Table 1). He was discharged home 12 days after being hospitalized.

A hereditary cause for HLH was not investigated due the prompt improvement without HLH-targeted therapy.

HLH is a potentially fatal hyperinflammatory condition caused by a highly stimulated but ineffective immune response [1]. It has been described as a familial disorder (due to defects in Nk citotoxicity) and as a sporadic one [2]. The latter has been associated with infections, malignancies, or rheumatologic disorders [3].

Infection-associated HLH can be triggered by virus, bacteria, fungi, or protozoa [1-4], but P. falciparum has rarely been reported as a cause of HLH [5-7], especially in children [10].

A deranged immune response is the cause of HLH, and the associated cytokine storm is responsible for the majority of the clinical and laboratory abnormalities [1-4]. The clinical diagnosis is established fulfilling five of the eight HLH-2004 criteria [1]. Noteworthy are the facts that hemophagocytosis is not required for establishing the diagnosis, that ferritin levels above $10,000 \mathrm{ng} / \mathrm{mL}$ are highly specific for HLH and that very high levels of $\operatorname{sIL} 2 \mathrm{R} \alpha$ are almost never seen outside HLH [3]. 
Table 1 Laboratory data performed on admission day (day 1), during hospitalization (between days 2 and 3), and at discharge (day 12)

\begin{tabular}{|c|c|c|c|}
\hline Laboratory evaluation & Day 1 & Day 2-3 & Day 12 \\
\hline Hemoglobin (g/dL) & 13.6 & 8.9 & 11.7 \\
\hline $\operatorname{WBC}\left(\times 10^{9} / \mathrm{L}\right)$ & 3.8 & 3.8 & 9.6 \\
\hline $\mathrm{ANC}\left(\times 10^{9} / \mathrm{L}\right)$ & 1.99 & 0.94 & 4.22 \\
\hline Platelet count $\left(\times 10^{9} / \mathrm{L}\right)$ & 21 & 9 & 502 \\
\hline PT (s)/INR/APTT (s) & $11.1 / 0.97 / 37$ & $16.6 / 1.45 / 53.3$ & $10.8 / 0.95 / 30.8$ \\
\hline Fibrinogen $(\mathrm{g} / \mathrm{L})$ & - & 0.6 & 1.5 \\
\hline D-dimer $(\mu \mathrm{g} / \mathrm{mL})$ & - & 13.288 & 2.382 \\
\hline $\mathrm{CRP}(\mathrm{mg} / \mathrm{L})$ & 73.9 & 81.3 & 2.9 \\
\hline AST/ALT/LDH (U/L) & $147 / 84 / 1063$ & 139/76/1411 & $53 / \mathbf{5 3} / \mathbf{5 1 0}$ \\
\hline GGT/ ALP (U/L) & $281 / 605$ & $190 / 626$ & $141 / 622$ \\
\hline T-Bil/D-Bil (mg/dL) & $10.53 / 6.09$ & $10.91 / 6.71$ & $2.33 / 0.87$ \\
\hline Triglycerides (mg/dL) & 91 & 306 & 197 \\
\hline Albumin $(\mathrm{g} / \mathrm{L})$ & - & 21 & 36 \\
\hline BUN/creatinine $(\mathrm{mg} / \mathrm{dL})$ & $34 / 0.46$ & $51 / 0.62$ & $12 / 0.20$ \\
\hline $\mathrm{Na}(\mathrm{mEq} / \mathrm{L})$ & 129 & 135 & 139 \\
\hline Ferritin $(\mathrm{ng} / \mathrm{mL})$ & - & 5890 & 734 \\
\hline $\mathrm{sCD} 25(\mathrm{U} / \mathrm{mL})$ & - & 4352 & - \\
\hline Plasmodium falciparum & $\begin{array}{l}\text { Positive antigenemia } \\
\text { Trophozoites on } \\
\text { peripheral blood smear } \\
\text { Parasite density } 0 \%\end{array}$ & $\begin{array}{l}\text { Positive antigenemia } \\
\text { Trophozoites on } \\
\text { peripheral blood smear }\end{array}$ & $\begin{array}{l}\text { Negative } \\
\text { antigenemir }\end{array}$ \\
\hline $\begin{array}{l}\text { EBV, CMV and PVB19 serology, } \\
\text { blood cultures, O\&P test }\end{array}$ & Negative & & \\
\hline
\end{tabular}

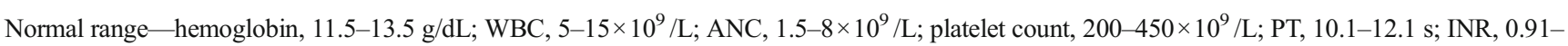
1.11; APTT, 26-36 s; fibrinogen, 1.57-4 g/L; D-dimer, <0.23 $\mu \mathrm{g} / \mathrm{mL}$; CRP, $<5 \mathrm{mg} / \mathrm{L}$; AST 15-60 U/L; ALT, <39 U/L; LDH, 110-295 U/L; GGT, <22 U/L; ALP, 86-362 U/L; T-Bil, 0.3-1.2 mg/dL; D-Bil, 0-0.2 mg/dL; triglycerides, <150 mg/dL; albumin, 35-52 g/L; BUN, $10.8-38.4 \mathrm{mg} / \mathrm{dL}$; creatinine, 0.16-0.39 mg/dL; Na, 136-145 mEq/L; ferritin, 24-336 ng/mL; sCD25, <1,000 U/mL. Bold numbers - abnormal values

$W B C$ white blood cell, $A N C$ absolute neutrophil count, $P T$ prothrombin time, INR international normalized ratio, APTT activated partial thromboplastin time, $C R P$ C-reactive protein, $A S T$ aspartate aminotransferase, $A L T$ alanine aminotransferase, $L D H$ lactate dehydrogenase, GGT gamma-glutamyl transferase, $A L P$ alkaline phosphatase, $T$-Bil total bilirubin, $D$-Bil direct bilirubin, $B U N$ blood urea nitrogen, $N a$ sodium, $s C D 25$ soluble CD25, $E B V$ Epstein-Barr virus, CMV Cytomegalovirus, PVB19 human parvovirus B19, O\&P ova and parasite (stool) test

The authors believe that despite being rarely described, HLH-associated malaria should be suspected in patients with severe malaria and unexpected multiorgan failure. Experimental studies have demonstrated that several soluble exoantigens of $P$. falciparum induce inappropriate macrophage activation and a Th1-stimulated hypercytokinemia with excessive production of the TNF- $\alpha$ and INF- $\gamma$ [8], which are some of the major cytokines responsible for HLH. This has also been well described with other infectious agents, such as EBV [9].

Most cases of malaria-induced HLH reported in literature have responded completely to antimalarial therapy alone [5-7], as observed in our case. Nevertheless, like in EBVassociated HLH [10], in the rare cases where there is progression of HLH despite appropriate antimalarial therapy, a stepwise approach can probably be applied, in order to allow disease control without jeopardizing the infection control.

Conflict of Interest The authors declare that they have no conflict of interest.

\section{References}

1. Henter JI, Horne A, Aricó M, Egeler RM, Filipovich AH, Imashuku S, Ladisch S, McClain K, Webb D, Winiarski J, Janka G (2007) HLH-2004: diagnostic and therapeutic guidelines for hemophagocytic lymphohistiocytosis. Pediatr Blood Cancer 48(2): 124-131

2. Janka GE (2007) Familial and acquired hemophagocytic lymphohistiocytosis. Eur J Pediatr 166(2):95-109

3. Filipovich AH (2011) The expanding spectrum of hemophagocytic lymphohistiocytosis. Curr Opin Allergy Clin Immunol 11(6):512-516

4. Canna SW, Behrens EM (2012) Making sense of the cytokine storm: a conceptual framework for understanding, diagnosing, and treating hemophagocytic syndromes. Pediatr Clin N Am 59(2):329-344

5. Rehman JU, Bhabri N, Waleed A, Maulawi A, Aslam M (2012) Falciparum malaria in a patient with sickle cell trait with hemophagocytosis and secondary pancytopenia. Ann Hematol 91(8): 1329-1330

6. Ohnishi K, Mitsui K, Komiya N, Iwasaki N, Akashi A, Hamabe Y (2007) CLINICAL case report: falciparum malaria with hemophagocytic syndrome. Am J Trop Med Hyg 76(6): 1016-1018 
7. Sermet-Gaudelus I, Abadie V, Stambouli F, Hennequin C, Lenoir G, Gendrel D (2000) Haemophagocytic syndrome in Plasmodium falciparum malaria. Acta Paediatr 89(3):368369

8. Kwiatkowski D, Hill AV, Sambou I, Twumasi P, Castracane J, Manogue KR, Cerami A, Brewster DR, Greenwood BM (1990) TNF concentration in fatal cerebral, non-fatal cerebral, and uncomplicated Plasmodium falciparum malaria. Lancet 336(8725): 1201-1204

9. Usmani GN, Woda BA, Newburger PE (2013) Advances in understanding the pathogenesis of HLH. Br J Haematol 161(5):609-622

10. Imashuku S (2011) Treatment of Epstein-Barr virus-related hemophagocytic lymphohistiocytosis (EBV-HLH); update 2010. J Pediatr Hematol Oncol 33(1):35-39 